\title{
Factors associated with the length of stay in total knee arthroplasty patients with the enhanced recovery after surgery model
}

\author{
Guoqing $\mathrm{Li}^{1,2+}$, Jian Weng ${ }^{1,2+}$, Chang $\mathrm{Xu}^{1,2}$, Deli Wang ${ }^{1,2}$, Ao Xiong ${ }^{1,2}$ and Hui Zeng ${ }^{1,2^{*}}$ (D)
}

\begin{abstract}
Objectives: The purpose of this study is to identify the factors that influence the length of stay (LOS) in total knee arthroplasty (TKA) patients with an enhanced recovery after surgery (ERAS) program.

Methods: Information from 167 patients (31 males and 136 females, range from 43 years to 88 years old) who underwent the unilateral elective primary TKA from January 2017 to January 2019 were reviewed retrospectively. Factors were analyzed by single-factor variance and multi-factor linear regression.

Results: By single-factor variance analysis, American Society of Anesthesiologists (ASA) physical status classification system, pre-operation albumin, pre-operation erythrocyte sedimentation rate (ESR), primary and merge diseases, hidden blood loss, and length of operation were correlated with $\operatorname{LOS}(P<0.05)$. Multi-factor linear regression results suggested that gender, ASA class, pre-operation Alb, and pre-operation ESR were associated with LOS $(P<0.05)$. Moreover, ASA class 3 ( $B$ value 4.84), pre-operation Alb $<30 \mathrm{~g} / \mathrm{L}$ ( $B$ value 18.33), and pre-operation $\mathrm{ESR}>15 \mathrm{mmol} / \mathrm{h}$ ( $B$ value 2.21 ) could increase the LOS, while males ( $B$ value -3.56 ) had a shortened LOS.
\end{abstract}

Conclusions: Overall, our research found that female, ASA class 3, pre-operation Alb $<30 \mathrm{~g} / \mathrm{L}$, and pre-operation ESR $>15 \mathrm{mmol} / \mathrm{h}$ could extend LOS in TKA patients with ERAS.

Keywords: Enhanced recovery after surgery, Total knee arthroplasty, Length of stay, Factors

\section{Introduction}

End-stage knee diseases could cause patients great inconvenience, and the population of these patients increases continuously [1]. Total knee arthroplasty (TKA) is an effective treatment for end-stage knee diseases, and it had been matured with decades of development and continuous research. Enhanced recovery after surgery (ERAS) has made great success for patients after TKA, which shortens the recovery time and improves patients' satisfaction. However, factors that might extend the length of stay (LOS) of patients remained to be identified [2-4]. In our study, we aim to investigate factors

\footnotetext{
* Correspondence: zenghui_36@163.com

${ }^{+}$Guoqing Li and Jian Weng contributed equally to this work.

${ }^{1}$ National \& Local Joint Engineering Research Center of Orthopaedic

Biomaterials, Peking University Shenzhen Hospital, Shenzhen, People's Republic of China

${ }^{2}$ Department of Bone \& Joint Surgery, Peking University Shenzhen Hospital, Shenzhen, China
}

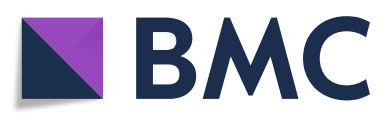

(c) The Author(s). 2019 Open Access This article is distributed under the terms of the Creative Commons Attribution 4.0 International License (http://creativecommons.org/licenses/by/4.0/), which permits unrestricted use, distribution, and

reproduction in any medium, provided you give appropriate credit to the original author(s) and the source, provide a link to the Creative Commons license, and indicate if changes were made. The Creative Commons Public Domain Dedication waiver (http://creativecommons.org/publicdomain/zero/1.0/) applies to the data made available in this article, unless otherwise stated. affecting the LOS of patients with ERAS after TKA treatment using a retrospective analysis.

\section{Materials and methods Applications of ERAS model}

ERAS was proposed by Kehlet et al. [5] firstly. It can decrease the surgical stress and complications, shorten the LOS, and improve patient satisfaction. Edwards et al. reported that the ERAS model was safe and effective for elderly patients older than 80 years [6]. Previously, our group developed the relevant diagnosis and treatment plan for patients with end-stage knee diseases, according to the ERAS consensus guide for joint arthroplasty in China [7]. A retrospective analysis of the Institutional Joint Registry was performed to identify factors affecting the LOS of patients. The study protocol was approved by the Human Subject Committee at Ethics Committee of Peking University Shenzhen Hospital (Ethics Committee of Peking University Shenzhen Hospital (research) 
[2019] 38th). The investigation of the LOS of TKA was performed carefully to ensure the validity. Patients who were lost follow-up, who underwent bilateral TKA in the same period, unilateral condyle arthroplasty, or renovation, and had primary diseases without osteoarthritis/ rheumatoid arthritis (OA/RA) were excluded. These data were collected retrospectively from the medical records. In total, 167 patients who underwent surgery in the Department of Bone and Joint in the Peking University Shenzhen Hospital were enrolled in this study (Fig. 1).

\section{Study variables}

Variables analyzed in the study included the following: (1) demographic characteristics: age, gender, mass, height, and body mass index (BMI); (2) preoperative blood test: hemoglobin $(\mathrm{Hb})$, albumin, C-reactive protein (CRP), and ESR; (3) postoperative blood test: $\mathrm{Hb}$, Alb, CRP, ESR, ASA class, and operative time; (4) transfusion and change of hemoglobin $(\triangle \mathrm{Hb}) ;(5)$ the use of urinary duct, tourniquet, and incision drainage, primary diseases, and merge diseases; and (6) date of admission and discharge.

\section{Discharge criteria}

The discharge criteria vary worldwide [8]. The discharge criteria for patients after TKA in our hospitals are as follows: (1) patients are willing to be discharged; (2) patients' vital signs are normal and stable, while the performance of appetite and sleep has returned to normal; (3) the incision has healed with no signs of infection, and hematological results are in the normal range; (4) patients have passed the functional exercise test, and they can walk alone with the help of mobility aids; (5) visual pain score $\leq 3$; and (6) active knee joint flexor $\geq 90^{\circ}$, passive flexural $\geq 110^{\circ}$, and muscle strength grade $\geq 4$.

\section{Statistical analysis}

All statistical analyses were carried out by SPSS software (version 23.0). The data is represented by mean \pm standard deviation. The single factor adopted the chisquare test, and the multi-factor adopted the linear regression analysis. $P<0.05$ is considered statistically significant.

\section{Results}

\section{Single-factor chi-square analysis}

The single-factor chi-square analysis of demographic characteristics and LOS showed that demographic characteristics, including sex, age, and BMI, had no significant correlation with LOS $(P>0.05)$ (Table 1).

Some items in the preoperative blood tests were related with the LOS. Preoperative Alb, preoperative ESR, primary disease, merge disease, and ASA class were associated with LOS. The variation was statistically significant $(P<0.05)$. At the same time, preoperative $\mathrm{Hb}$ and preoperative CRP had no significant correlation with LOS $(P>0.05)$ (Table 2).

The hidden blood loss (pre-operation $\mathrm{Hb}$ ) and the operation duration in surgical factors were statistically correlated with LOS for TKA patients, and there was a significant difference $(P<0.05)$. However, the start time of operation, intraoperative blood transfusion, the use of urinary duct, tourniquet, and incision drainage tube had no significant correlation with LOS $(P>0.05)$ (Table 3).

The influence of pre-operation ESR, ASA class, and pre-operation Alb on the LOS in TKA patients was reflected in regression curves (Fig. 2). Among these variables, ASA class and preoperative ESR had a positive correlation with LOS of patients, while preoperative Alb had a negative correlation with LOS of patients.

Moreover, the results of single-factor variance analysis in this study suggested that some factors were significantly associated with LOS $(P<0.05)$, such as preoperative Alb, preoperative ESR, primary disease, merge disease, and ASA class. Combining the reported literatures and the clinical practice, factors that showed no statistical significance in the single-factor variance analysis $(P>0.05)$ are included in the multi-factor linear regression analysis.

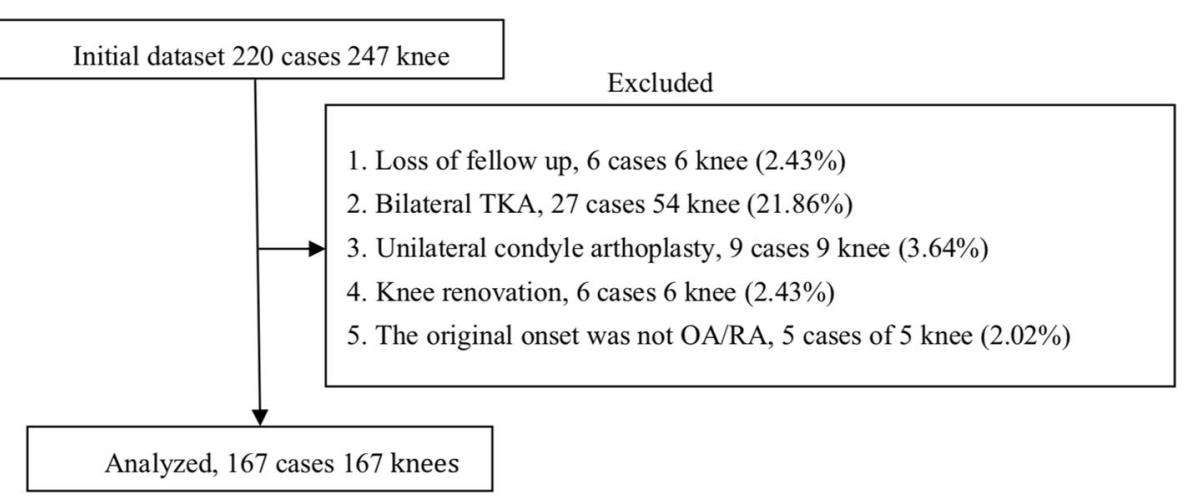

Fig. 1 Flowchart that illustrates patients excluded from the study 
Table 1 Single-factor chi-square analysis of the demographic characteristics ( $N=167)$

\begin{tabular}{|c|c|c|c|c|c|c|}
\hline Factors & Classification & Number & Percent & Mean \pm SD & $F$ value & $P$ value \\
\hline \multirow[t]{2}{*}{ Gender } & Female & 136 & 81.4 & $19.24 \pm 6.72$ & 0.275 & 0.601 \\
\hline & Male & 31 & 18.60 & $18.55 \pm 6.37$ & & \\
\hline \multirow[t]{5}{*}{ Age (year) } & $Y<50$ & 6 & 3.60 & $19.83 \pm 3.60$ & 0.540 & 0.706 \\
\hline & $50 \leq Y<60$ & 22 & 13.20 & $19.09 \pm 4.51$ & & \\
\hline & $60 \leq Y<70$ & 74 & 44.30 & $18.32 \pm 7.25$ & & \\
\hline & $70 \leq Y<80$ & 53 & 31.70 & $20.02 \pm 6.45$ & & \\
\hline & $80 \leq Y$ & 12 & 7.20 & $19.67 \pm 8.15$ & & \\
\hline \multirow[t]{6}{*}{ BMI $\left(\mathrm{kg} / \mathrm{m}^{2}\right)$} & $\mathrm{BMI}<18.5$ & 3 & 1.80 & $19.67 \pm 5.51$ & 0.620 & 0.685 \\
\hline & $18.5 \leq \mathrm{BMI}<24$ & 59 & 35.30 & $19.05 \pm 7.08$ & & \\
\hline & $24 \leq \mathrm{BMI}<28$ & 63 & 37.70 & $19.49 \pm 7.17$ & & \\
\hline & $28 \leq \mathrm{BMI}<30$ & 20 & 12.00 & $17.65 \pm 5.32$ & & \\
\hline & $30 \leq \mathrm{BMI}<40$ & 19 & 11.40 & $18.68 \pm 2.89$ & & \\
\hline & $40 \leq \mathrm{BMl}$ & 3 & 1.80 & $24.33 \pm 13.01$ & & \\
\hline
\end{tabular}

$B M I$ body mass index

\section{Multi-factor linear regression analysis}

The results suggested that gender, ASA class, preoperative Alb, and preoperative ESR were significantly correlated with LOS in TKA patients $(P<0.05)$. Moreover, female patients, ASA class 3, pre-operation albu$\min <30 \mathrm{~g} / \mathrm{L}$, and pre-operation ESR $>15 \mathrm{mmol} / \mathrm{h}$ were the risk factors for the prolongation of LOS in TKA patients, while the other factors were not significantly correlated with LOS $(P>0.05)$ (Table 4$)$.

\section{Discussion}

Currently, ERAS program has performed well for patients after TKA. The ERAS program could decrease complications of surgery and shorten the LOS, further allowing patients to recover and discharge earlier. However, many factors may prolong the LOS in TKA patients, which are still unclear. Therefore, factors that caused the LOS prolongation in TKA patients should be identified to establish a better ERAS model.

Table 2 Single-factor chi-square analysis of preoperative variables $(N=167)$

\begin{tabular}{|c|c|c|c|c|c|c|}
\hline Factors & Classification & Number & Percent & Mean \pm SD & $F$ value & $P$ value \\
\hline \multirow[t]{6}{*}{ Pre-operation $\mathrm{Hb}(\mathrm{g} / \mathrm{L})$} & $\mathrm{Hb}<100$ & 5 & 3.00 & $20.00 \pm 5.79$ & \multirow[t]{6}{*}{5.457} & \multirow[t]{6}{*}{0.104} \\
\hline & $100 \leq \mathrm{Hb}<110$ & 13 & 7.80 & $22.08 \pm 10.17$ & & \\
\hline & $110 \leq \mathrm{Hb}<120$ & 23 & 13.80 & $21.74 \pm 7.09$ & & \\
\hline & $120 \leq \mathrm{Hb}<130$ & 52 & 31.10 & $17.29 \pm 4.68$ & & \\
\hline & $130 \leq \mathrm{Hb}<140$ & 46 & 27.50 & $18.87 \pm 7.60$ & & \\
\hline & $140 \leq \mathrm{Hb}$ & 28 & 16.80 & $19.21 \pm 4.98$ & & \\
\hline \multirow[t]{2}{*}{ Pre-operation albumin $(\mathrm{g} / \mathrm{L})$} & $<30$ & 2 & 1.20 & $33.50 \pm 4.95$ & \multirow[t]{2}{*}{4.675} & \multirow[t]{2}{*}{0.002} \\
\hline & $\geq 30$ & 165 & 98.80 & $18.94 \pm 6.48$ & & \\
\hline \multirow[t]{2}{*}{ Pre-operation ESR (mm/h) } & $<15$ & 77 & 46.10 & $17.71 \pm 5.22$ & \multirow[t]{2}{*}{6.560} & \multirow[t]{2}{*}{0.011} \\
\hline & $\geq 15$ & 90 & 53.90 & $20.31 \pm 7.47$ & & \\
\hline \multirow[t]{2}{*}{ Pre-operation CRP (mg/L) } & $<5$ & 44 & 26.30 & $18.55 \pm 6.48$ & \multirow[t]{2}{*}{0.371} & \multirow[t]{2}{*}{0.691} \\
\hline & $\geq 5$ & 122 & 73.70 & $19.29 \pm 6.73$ & & \\
\hline \multirow[t]{2}{*}{ Primary disease } & RA & 16 & 9.60 & $23.50 \pm 7.80$ & \multirow[t]{2}{*}{8.050} & \multirow[t]{2}{*}{0.005} \\
\hline & $\mathrm{OA}$ & 151 & 90.40 & $18.65 \pm 6.36$ & & \\
\hline \multirow[t]{2}{*}{ Merge disease } & No & 112 & 67.10 & $18.36 \pm 5.96$ & \multirow[t]{2}{*}{4.509} & \multirow[t]{2}{*}{0.035} \\
\hline & Yes & 55 & 32.90 & $20.65 \pm 7.68$ & & \\
\hline \multirow[t]{3}{*}{ ASA class } & 1 & 38 & 22.80 & $16.61 \pm 5.17$ & \multirow[t]{3}{*}{3.844} & \multirow[t]{3}{*}{0.023} \\
\hline & 2 & 120 & 71.90 & $19.75 \pm 6.53$ & & \\
\hline & 3 & 9 & 5.40 & $21.22 \pm 10.76$ & & \\
\hline
\end{tabular}


Table 3 Single-factor chi-square analysis of operational variables $(N=167)$

\begin{tabular}{|c|c|c|c|c|c|c|}
\hline Factors & Classification & Number & Percent & Mean \pm SD & $F$ value & $P$ value \\
\hline \multirow[t]{5}{*}{ Hidden blood loss $(\Delta \mathrm{Hb})(\mathrm{g} / \mathrm{L})$} & $\Delta \mathrm{Hb}<10$ & 30 & 18.00 & $19.30 \pm 6.56$ & 2.729 & 0.031 \\
\hline & $10 \leq \Delta \mathrm{Hb}<20$ & 56 & 33.50 & $20.77 \pm 8.23$ & & \\
\hline & $20 \leq \Delta \mathrm{Hb}<30$ & 43 & 25.70 & $17.84 \pm 4.54$ & & \\
\hline & $30 \leq \Delta \mathrm{Hb}<40$ & 32 & 19.20 & $18.94 \pm 5.55$ & & \\
\hline & $40 \leq \Delta \mathrm{Hb}$ & 6 & 3.60 & $12.83 \pm 3.66$ & & \\
\hline \multirow[t]{2}{*}{ Surgery begins } & < 14:00 P.M. & 53 & 31.70 & $18.86 \pm 6.60$ & 0.525 & 0.470 \\
\hline & $\geq 14: 00$ P.M. & 114 & 68.30 & $19.66 \pm 6.75$ & & \\
\hline \multirow[t]{5}{*}{ Op-duration T (h) } & $T<2$ & 24 & 13.50 & $17.92 \pm 3.96$ & 4.524 & 0.002 \\
\hline & $2 \leq \mathrm{T}<3$ & 97 & 55.90 & $18.38 \pm 5.49$ & & \\
\hline & $3 \leq \mathrm{T}<4$ & 35 & 25.20 & $23.00 \pm 9.78$ & & \\
\hline & $4 \leq T<5$ & 3 & 1.40 & $15.33 \pm 2.08$ & & \\
\hline & $5 \leq T$ & 8 & 4.00 & $16.00 \pm 3.21$ & & \\
\hline \multirow[t]{2}{*}{ Transfusion } & No & 152 & 91.00 & $18.82 \pm 6.15$ & 2.682 & 0.071 \\
\hline & Yes & 15 & 9.00 & $22.07 \pm 10.25$ & & \\
\hline \multirow[t]{2}{*}{ Urine tube } & No & 33 & 19.80 & $17.70 \pm 6.46$ & 1.882 & 0.172 \\
\hline & Yes & 134 & 80.20 & $19.46 \pm 6.67$ & & \\
\hline \multirow[t]{2}{*}{ Drainage } & No & 147 & 88.00 & $19.09 \pm 6.56$ & 8.345 & 0.894 \\
\hline & Yes & 20 & 12.00 & $19.30 \pm 7.36$ & & \\
\hline \multirow[t]{2}{*}{ Tourniquet } & No & 2 & 1.20 & $12.50 \pm 3.54$ & 2.021 & 0.157 \\
\hline & Yes & 165 & 98.80 & $19.19 \pm 6.63$ & & \\
\hline
\end{tabular}

Most of the relevant researches were conducted in Europe and America, whereas Chinese patients with ERAS program were less covered [9]. Thus, it is of great significance to investigate the clinical situation of TKA patients with ERAS program in China and identify the influencing factors of LOS prolongation. In this study, the influencing factors of LOS were analyzed retrospectively to shorten LOS and optimize the ERAS model, further promoting the TKA surgery.

Many factors may influence the LOS in ERAS model, such as gender. Gender was reported to associate with knee osteoarthritis (KOA) [10-13]. The satisfaction rate of female patients was relatively low and the LOS was relatively long, compared with other patients. Our results suggested that female gender was a risk factor for LOS prolongation in the application of ERAS model. Compared with males, females had a higher probability of getting urinary tract infection and deep venous thrombosis $[14,15]$, further prolonging the LOS. Besides, the lower limb dysfunction and muscle weakness might lead to a slower postoperative rehabilitation, resulting in LOS extension. In the ERAS model, the orthopedic surgeon should pay more attention on the female patients and design the individualized therapy. Various interventions in the ERAS model might be effective to shorten the LOS. For example, strengthening the psychological education to the patient to reduce and eliminate their anxiety and fear, avoiding the retention

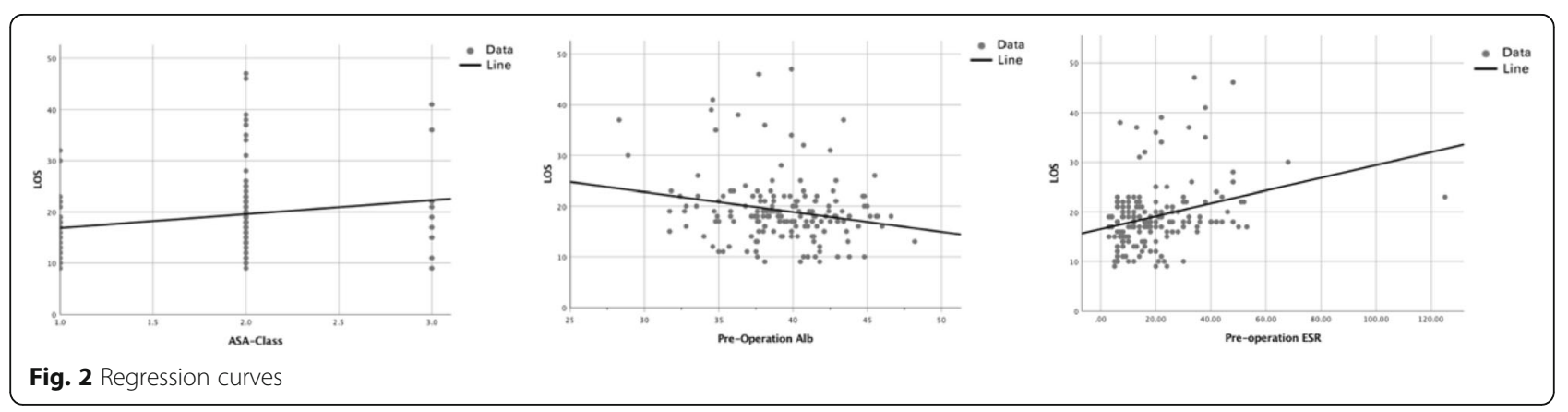


Table 4 Multi-factor linear regression analysis $(N=167)$

\begin{tabular}{|c|c|c|c|c|c|}
\hline Factors & $\beta$ & S.E & $T$ value & $P$ value & $95 \% \mathrm{Cl}$ \\
\hline \multicolumn{6}{|l|}{ Gender $\left(X_{1}\right)$} \\
\hline Female & \multicolumn{5}{|c|}{ (Control group) } \\
\hline Male & -3.56 & 1.58 & -2.25 & 0.03 & $-6.69 \sim-0.42$ \\
\hline \multicolumn{6}{|l|}{ Age $\left(X_{2}\right)$} \\
\hline$Y<50$ & \multicolumn{5}{|c|}{ (Control group) } \\
\hline $50 \leq Y<60$ & 2.80 & 3.30 & 0.85 & 0.40 & $-3.72 \sim 9.34$ \\
\hline $60 \leq Y<70$ & 0.26 & 3.33 & 0.08 & 0.94 & $-6.32 \sim 6.86$ \\
\hline $70 \leq Y<80$ & -0.82 & 3.36 & -0.24 & 0.81 & $-7.46 \sim 5.83$ \\
\hline $80 \leq Y$ & -0.67 & 3.88 & -0.17 & 0.86 & $-8.35 \sim 7.01$ \\
\hline \multicolumn{6}{|l|}{$\operatorname{ASA}$ class $\left(X_{3}\right)$} \\
\hline 1 & \multicolumn{5}{|c|}{ (Control group) } \\
\hline 2 & 2.49 & 1.36 & 1.83 & 0.07 & $-0.21 \sim 5.18$ \\
\hline 3 & 4.84 & 2.51 & 1.92 & 0.049 & $-0.14 \sim 9.81$ \\
\hline \multicolumn{6}{|l|}{ Duration $\mathrm{T}\left(X_{4}\right)$} \\
\hline $\mathrm{T}<2 \mathrm{H}$ & \multicolumn{5}{|c|}{ (Control group) } \\
\hline $2 \mathrm{H} \leq \mathrm{T}<3 \mathrm{H}$ & 1.07 & 2.13 & 0.50 & 0.62 & $-3.16 \sim 5.29$ \\
\hline $2 \mathrm{H} \leq \mathrm{T}<3 \mathrm{H}$ & 8.09 & 2.86 & 2.84 & 0.005 & $2.44 \sim 13.74$ \\
\hline $4 \mathrm{H} \leq \mathrm{T}<5 \mathrm{H}$ & 5.26 & 6.61 & 0.80 & 0.43 & $-7.83 \sim 18.35$ \\
\hline$T \geq 5 \mathrm{H}$ & 4.71 & 5.74 & 0.82 & 0.41 & $-6.67 \sim 16.09$ \\
\hline \multicolumn{6}{|l|}{$\begin{array}{l}\text { Pre-operation } \\
\text { albumin }\left(X_{5}\right)\end{array}$} \\
\hline$\geq 30 \mathrm{~g} / \mathrm{L}$ & \multicolumn{5}{|c|}{ (Control group) } \\
\hline$<30 \mathrm{~g} / \mathrm{L}$ & 18.33 & 5.41 & 3.39 & 0.001 & $7.61 \sim 29.05$ \\
\hline \multicolumn{6}{|l|}{$\begin{array}{l}\text { Pre-operation } \\
\operatorname{ESR}\left(X_{6}\right)\end{array}$} \\
\hline$<15 \mathrm{mmol} / \mathrm{h}$ & \multicolumn{5}{|c|}{ (Control group) } \\
\hline$\geq 15 \mathrm{mmol} / \mathrm{h}$ & 2.21 & 1.01 & 2.18 & 0.03 & $0.21 \sim 4.22$ \\
\hline \multicolumn{6}{|l|}{$\begin{array}{l}\text { Primary disease } \\
\left(X_{7}\right)\end{array}$} \\
\hline $\mathrm{KOA}$ & \multicolumn{5}{|c|}{ (Control group) } \\
\hline KRA & -3.04 & 2.15 & -1.42 & 0.16 & $-7.30 \sim 1.21$ \\
\hline \multicolumn{6}{|l|}{$\begin{array}{l}\text { Merge disease } \\
\left(X_{8}\right)\end{array}$} \\
\hline No & \multicolumn{5}{|c|}{ (Control group) } \\
\hline Yes & 1.97 & 1.12 & 1.76 & 0.08 & $-0.54 \sim 2.92$ \\
\hline \multicolumn{6}{|l|}{$\begin{array}{l}\text { Tourniquet } \\
\left(X_{9}\right)\end{array}$} \\
\hline No & \multicolumn{5}{|c|}{ (Control group) } \\
\hline Yes & 8.60 & 4.58 & 1.88 & 0.06 & $-0.48 \sim 17.68$ \\
\hline
\end{tabular}

ASA American Society of Anesthesiologists, ESR erythrocyte sedimentation, $K O A$ knee osteoarthritis, KRA knee rheumatoid arthritis

catheterization and removing it in the early stage to prevent the urinary tract infection, adopting the combination therapy of physiotherapy and pharmacotherapy to avoid the deep venous thrombosis, and strengthening the early-stage rehabilitation exercise to promote the recovery of patients. All the strategies could optimize the ERAS model and shorten LOS.

ASA class indicates the risk of operation and anesthesia in patients. ASA class would affect the LOS, and the LOS would be prolonged half day per two levels of ASA class. If the ASA score was over 2, the probability of adverse events and the usage of opioid use would increase. Based on the ASA score, the anesthesiologist could optimize the anesthetic methods to shorten the LOS. Our study found that the higher ASA class (ASA class > 3) could increase the LOS. Thus, the orthopedic surgeon should evaluate the complexity of disease and risk of surgery during the perioperative period to identify the complicating disease and should do positive interventions. Besides, making appropriate anesthesia measures with the consultation of anesthetist and designing the relative prevention procedures could reduce stress response or complications in patients, which might be beneficial for recovery.

Nutrition support is one of the key elements in the ERAS model. The preoperative albumin reflects the nutrition status of patients, which participates in the promotion of incision healing. A high pre-operative Alb could promote the incision healing, while a low serum Alb would lead to a variety of complications or even death $[16,17]$. Our study found that patients with preoperative $\mathrm{Alb}<30 \mathrm{~g} / \mathrm{L}$ had a longer LOS. Thus, the surgeon should pay more attention to the Alb of the patient and do periodical inspection. TKA can increase stress response and cause trauma, further leading to the impaired immunity and nutritional metabolism disorders [18]. Malnourished patients are too weak to overcome stress response, then, the recovery process will be slow and the LOS will be prolongated. Thus, during the perioperative period, the surgeon should consult with the nutritionist to assess the risk of malnutrition in patients and do the early intervention to assist the recovery of patients. Preoperative selective feeding, shortening the period of fasting, and encouraging early feeding after surgery would reduce the stress response and the possibility of complications. Besides, high-protein food could increase the protein levels in vivo and improve the incision healing. Maintaining the normal enteral nutrition could be effective. Combining the position adjustment and drug intervention could prevent the postoperative nausea and vomiting, further promoting the nutritional support.

Reducing inflammation and stress response are major parts of the ERAS model. ESR is a sensitive inflammatory indicator in serum, which can be used to predict the probability of infection. However, it cannot clearly indicate the clearance of the infection and direct the implant timing of the prosthesis [19-21]. Our study indicated that preoperative ESR $\geq 15 \mathrm{~mm} / \mathrm{h}$ could lead to the prolongation of LOS. The surgeon should pay more 
attention to the ESR in patients and maintain it in the normal range. Strict aseptic operation and appropriate use of antibiotics could prevent infection. However, in clinical practice, we noticed that some patients' ESR level were high before surgery and declined after surgery. This clinical phenomenon might be related with the primary diseases in patients, such as rheumatoid arthritis (RA). Thus, the surgeon should make individualized treatment schedule for patients with TKA, choose the surgery timing carefully, and strengthen the intervention in the perioperative period to shorten the LOS [22].

In addition, the operation time, primary diseases, and merge diseases might affect the LOS in patients. Sodhi et al. reported that the operation time was closely related to LOS [23]. Sizer et al. found that elder patients were easier to occur bleeding during operation and had increased complications [24]. Primary disease could affect patients' satisfaction and the LOS [25]. Early postoperative rehabilitation could help to shorten the LOS in patients [26]. This paper reported that the above factors were significantly correlated with the LOS in TKA patients by the singlefactor chi-square analysis $(P<0.05)$. However, the multifactor linear regression analysis did not support the finding, and the significant association between the above factors and the LOS was above 0.05 . This inconformity between the single-factor chi-square analysis and the multi-factor linear regression analysis might be explained by the limited sample amounts. We will increase the sample amounts and do the follow-up investigation in further research. Based on the current finding, we concluded that improving the surgical technique to shorten the time of operation, strengthening the hematology management to reduce the probability of bleeding and blood transfusion, enhancing the intervention of the active rehabilitation, and maintaining a regular follow-up might optimize the ERAS model and reduce the LOS.

\section{Conclusions}

To sum up, LOS is related with patients' satisfaction, while many factors might influence the LOS in TKA patients. Our study found that female, ASA class 3, preoperative albumin $<30 \mathrm{~g} / \mathrm{L}$, and preoperative ESR $>15$ $\mathrm{mmol} / \mathrm{h}$ were the risk factors to increase LOS. Some factors in this study did not appear to be statistically significant, which might be due to the small sample size. We will increase the sample size and follow-up on this study in the future. Our study suggests that the ERAS model should be optimized and designed on the individual's status to shorten LOS in TKA patients.

\section{Abbreviations}

ASA: American Society of Anesthesiologists; BMI: Body mass index; $\mathrm{Cl}$ : Confidence intervals; CRP: C-reactive protein; ERAS: Enhanced recovery after surgery; Hb: Hemoglobin; LOS: Length of stay; OA: Osteoarthritis; RA: Rheumatoid arthritis; TKA: Total knee arthroplasty

\section{Acknowledgements}

The authors sincerely acknowledge the entire staff of the Department of Bone \& Joint Surgery, Peking University Shenzhen Hospital, who offered assistance throughout the course of this study.

\section{Authors' contributions}

G-QL and JW reviewed and collected the database, conceived the design of the study, and prepared the manuscript. CX carried out the statistical analysis. D-LW and AX assisted with the statistical analysis and revision of the manuscript. $\mathrm{HZ}$ initiated and designed the study. All authors read and approved the final manuscript.

\section{Funding}

This study was funded by the fund of "San-Ming" Project of Medicine in Shenzhen (No. SZSM201612092), the Research and Development Projects of Shenzhen of P. R. China (No. JCYJ2017030711175218), and the basic research project of Peking University Shenzhen Hospital (No. JCYJ2018004).

\section{Availability of data and materials}

Please contact the author for data requests.

\section{Ethics approval and consent to participate}

The study protocol was approved by the Ethics Committee of Peking University Shenzhen Hospital (Ethics Committee of Peking University Shenzhen Hospital (research) [2019] 38th).

\section{Competing interests}

The authors declare that they have no competing interests.

Received: 17 May 2019 Accepted: 23 September 2019

Published online: 06 November 2019

\section{References}

1. Kurtz SM, et al. Impact of the economic downturn on total joint replacement demand in the United States: updated projections to 2021. J Bone Joint Surg Am. 2014;96(8):624-30.

2. Stowers MD, et al. Enhanced recovery after surgery in elective hip and knee arthroplasty reduces length of hospital stay. ANZ J Surg. 2016;86(6):475-9.

3. Deng QF, et al. Impact of enhanced recovery after surgery on postoperative recovery after joint arthroplasty: results from a systematic review and metaanalysis. Postgrad Med J. 2018;94(1118):678-93.

4. Stambough JB, et al. Rapid recovery protocols for primary total hip arthroplasty can safely reduce length of stay without increasing readmissions. J Arthroplast. 2015;30(4):521-6.

5. Wilmore DW, Kehlet H. Management of patients in fast track surgery. Bmj. 2001;322(7284):473-6.

6. Edwards PK, et al. Is rapid recovery hip and knee replacement possible and safe in the octogenarian patient? J Arthroplast. 2018;33(2):316-9.

7. Zhou Z, et al. Accelerated rehabilitation of hip and knee arthroplasty in China-expert consensus on perioperative management strategies. J Chin Bone Joint Surg. 2016;9(01):1-9.

8. Marsh J, et al. Significant cost savings and similar patient outcomes associated with early discharge following total knee arthroplasty. Can J Surg. 2019;62(1):20-4.

9. Zhang $\mathrm{S}$, et al. Preoperative predictive factors for accelerated rehabilitation and prolonged hospitalization of hip and knee arthroplasty. J Chin Bone Joint Surg. 2016:9(06):530-5 540 .

10. O'Connor Ml, Hooten EG. Breakout session: gender disparities in knee osteoarthritis and TKA. Clin Orthop Relat Res. 2011;469(7):1883-5.

11. Dalury DF, et al. Analysis of the outcome in male and female patients using a unisex total knee replacement system. J Bone Joint Surg Br. 2009;91(3): $357-60$

12. Gronbeck C, Cote MP, Halawi MJ. Predicting inpatient status after primary total knee arthroplasty in Medicare-aged patients. J Arthroplast. 2019.

13. Huang $Y$, et al. Reasons and factors behind post-total knee arthroplasty dissatisfaction in an Asian population. Ann Acad Med Singap. 2017;46(8): 303-9.

14. Basques BA, et al. Gender differences for hip and knee arthroplasty: complications and healthcare utilization. J Arthroplast. 2019. 
15. Lu Y, et al. Gender differences of venous thromboembolism risk after total hip and total knee arthroplasty: a meta-analysis. J Thromb Thrombolysis. 2016;41(4):556-62.

16. Rudasill SE, Ng A, Kamath AF. Preoperative serum albumin levels predict treatment cost in total hip and knee arthroplasty. Clin Orthop Surg. 2018; 10(4):398-406.

17. Ryan SP, et al. Albumin versus American Society of Anesthesiologists Score: which is more predictive of complications following total joint arthroplasty? Orthopedics. 2018;41(6):354-62

18. Weimann A, et al. ESPEN guideline: clinical nutrition in surgery. Clin Nutr. 2017:36(3):623-50

19. Nazem K, Motififard M, Yousefian M. Variations in ESR and CRP in total knee arthroplasty and total hip arthroplasty in Iranian patients from 2009 to 2011. Adv Biomed Res. 2016;5:148.

20. $\mathrm{Xu} \mathrm{C}$, et al. Preoperatively elevated serum inflammatory markers increase the risk of periprosthetic joint infection following total knee arthroplasty in patients with osteoarthritis. Ther Clin Risk Manag. 2018;14:1719-24.

21. Stambough JB, et al. Does change in ESR and CRP guide the timing of twostage arthroplasty reimplantation? Clin Orthop Relat Res. 2019;477(2):364-71.

22. Goodman SM, et al. 2017 American College of Rheumatology/American Association of Hip and Knee Surgeons Guideline for the perioperative management of antirheumatic medication in patients with rheumatic diseases undergoing elective total hip or total knee arthroplasty. J Arthroplast. 2017:32(9):2628-38

23. Sodhi $\mathrm{N}$, et al. Operative times can predict and are correlated with lengths-of-stay in primary total knee arthroplasty: a nationwide database study. J Arthroplast. 2019

24. Sizer SC, et al. Predicting blood loss in total knee and hip arthroplasty. Orthop Clin North Am. 2015;46(4):445-59.

25. Minator Sajjadi $M$, et al. Patient satisfaction following total knee arthroplasty: comparison of short-term results in rheumatoid arthritis and osteoarthritis. Arch Bone Jt Surg. 2019;7(1):61-6.

26. Yakkanti RR, et al. Impact of early mobilization on length of stay after primary total knee arthroplasty. Ann Transl Med. 2019;7(4):69.

\section{Publisher's Note}

Springer Nature remains neutral with regard to jurisdictional claims in published maps and institutional affiliations.

Ready to submit your research? Choose BMC and benefit from:

- fast, convenient online submission

- thorough peer review by experienced researchers in your field

- rapid publication on acceptance

- support for research data, including large and complex data types

- gold Open Access which fosters wider collaboration and increased citations

- maximum visibility for your research: over $100 \mathrm{M}$ website views per year

At $\mathrm{BMC}$, research is always in progress.

Learn more biomedcentral.com/submissions 